Limitations. The continued work of the REiNS Collaboration and the broader scientific community will be important in addressing the current limitations associated with these recommendations. First is the challenge of whether these PRO tools accurately assess the specific types of pain and physical functions being evaluated in clinical trials for individuals with NF when multiple factors may contribute to their pain experience or impact their daily functioning. Another issue is the lack of data in NF1, NF2, and SWN and whether the psychometric properties of the scale in these conditions will be consistent with those documented in the general population. Additionally, no PRO tools to date have shown the ability to measure pain and physical functioning adequately for all ages. In

\section{Comment: Clinical outcome assessments in transition}

The Response Evaluation in Neurofibromatosis and Schwannomatosis (REiNS) International Collaboration systematically evaluated existing patientreported outcome (PRO) measures of pain intensity, pain interference, and physical functioning as potential primary and secondary outcomes for neurofibromatosis trials. On the basis of 4 criteria-patient characteristics, item content, psychometric properties, and feasibility—specific measures were recommended. ${ }^{1}$ These recommendations are valuable for investigators designing clinical trials and can serve as a basis for developing improved outcome assessments for patients with these disorders.

In 2006, the US Food and Drug Administration (FDA) released a draft guidance on PRO measures that initiated a broader consideration of clinical outcome assessments (COAs) of "a patient's symptoms, overall mental state, or the effects of a disease or condition on how the patient functions."2 COAs are used in evaluating efficacy and safety, and include patient-reported, clinician-reported, observerreported, and performance outcome measures. Such measures should be used within a carefully defined context of use for which available data provide support. ${ }^{2}$ The FDA recently released a compendium of COAs that have either been used as a basis for regulatory decisions or are being developed in accord with its qualification program. ${ }^{3}$

In evaluating COAs, the FDA examines their content validity (e.g., as assessed by patient focus groups and cognitive interviewing), reliability, construct validity, and longitudinal measurement properties (e.g., ability to detect change, responder criteria). ${ }^{2}$ The REiNS recommendations were based on some of these characteristics, but most existing outcome measures fall short of the rigorous standards now being applied by the FDA. Indeed, as the REiNS investigators acknowledge, specification of the appropriate context of use (e.g., patient age, specific disorders) for pain and physical functioning measures in neurofibromatosis trials requires additional data. Systematic efforts to improve the validity, reliability, and responsiveness to change of COAs will ensure that clinical trial outcomes provide meaningful information about the treatment benefits and risks that patients consider most important.

1. Wolters PL, Martin S, Merker VL, et al. Patient-reported outcomes of pain and physical functioning in neurofibromatosis clinical trials. Neurology 2016;87(suppl 1):S4-S12.

2. US Food and Drug Administration. Clinical outcome assessment qualification program. Available at: http://www.fda.gov/Drugs/DevelopmentApprovalProcess/ DrugDevelopmentToolsQualificationProgram/ucm284077.htm. Accessed June 16, 2016.

3. US Food and Drug Administration. Clinical outcome assessment compendium (COA compendium): version 1. Available at: http://www.fda.gov/downloads/Drugs/ DevelopmentApprovalProcess/DevelopmentResources/UCM481225.pdf. Accessed June 16,2016

\section{Robert H. Dworkin, PhD}

From the Department of Anesthesiology, University of Rochester School of Medicine and Dentistry, NY. Study funding: No targeted funding reported.

Disclosure: Dr. Dworkin has received, in the past 12 months, research grants and contracts from the US Food and Drug Administration and US NIH, and compensation for activities involving clinical trial research methods from Abide, Adynxx, Aptinyx, Astellas, Biogen, Dong-A, Glenmark, Hope, Hydra, Immune, Medavante, Novartis, NsGene, Olatec, Periphagen, Phosphagenics, Reckitt Benckiser, Relmada, Semnur, Spinifex, Syntrix, Teva, Trevena, and Vertex. Go to Neurology.org for full disclosures. particular, researchers need to address the evaluation of these domains in children under 8 years old since NF trials are enrolling these younger participants. This challenge is reflected in our recommendation of 2 pain interference scales, as currently there are insufficient published data for establishing the validity of either measure in children and adults with NF. Identifying the most appropriate methods to assess children with significant cognitive impairments also needs to be addressed. Our group will update our recommendations in these specific areas in future publications.

To address the limitations noted above, PRO group members are using these recommended pain and physical functioning measures in descriptive studies and clinical trials with a wide age range of individuals who have all types of NF. Several of these PROs have been accepted into the FDA's Drug Development Tool COA Qualification Program ${ }^{12}$ and are being further studied with both qualitative and quantitative research methods ${ }^{11}$ to examine possible modifications and their use as NF clinical trial endpoints. The PRO working group also plans to form a subgroup that will focus on identifying measures to assess young children and individuals with significant cognitive impairments. Finally, researchers need to investigate the use of new methodologies in NF clinical trials to improve PRO data, such as using electronic administration to increase the accuracy and speed of data collection. ${ }^{39}$

The REiNS PRO group is working to identify PRO measures that can be used consistently as endpoints across trials to assess clinical benefit of treatments to reduce tumors or other disease manifestations in individuals with NF1, NF2, and SWN. The REiNS recommendations for PROs in the domains of pain and physical functioning are presented with the understanding that further evaluation of the measures is needed in the NF population. Our group encourages researchers to use these PRO measures in upcoming NF studies. Final consensus recommendations regarding the one specific pain interference measure and format of the PROMIS-PF scales to use in NF clinical trials will be disseminated in a future publication based on results of additional published research.

\section{AUTHOR CONTRIBUTIONS}

Pamela Wolters: design and conceptualization of the study, collection and interpretation of the data, drafting and revising the manuscript. Staci Martin: design and conceptualization of the study, collection and interpretation of the data, drafting and revising the manuscript. Vanessa Merker: study concept, collection and interpretation of the data, drafting and revising the manuscript. Jim Tonsgard: study concept, collection and interpretation of the data, drafting and revising the manuscript. Sondra Solomon: study concept, collection and interpretation of the data, drafting and revising the manuscript. Andrea Baldwin: study concept, collection and interpretation of the data, drafting and revising the manuscript. Amanda Bergner: study concept, collection and interpretation of the data, drafting and revising the manuscript. Karin Walsh: study concept, collection and interpretation of the data, drafting and revising the manuscript. 


\section{Neurology}

\section{Comment: Clinical outcome assessments in transition \\ Robert H. Dworkin \\ Neurology 2016;87;:S10 \\ DOI 10.1212/WNL.0000000000002936}

\section{This information is current as of August 15, 2016}

\section{Updated Information \& Services}

\section{References}

Permissions \& Licensing

Reprints including high resolution figures, can be found at: http://n.neurology.org/content/87/7_Supplement_1/S10.full

This article cites 1 articles, 0 of which you can access for free at: http://n.neurology.org/content/87/7_Supplement_1/S10.full\#ref-list-1

Information about reproducing this article in parts (figures,tables) or in its entirety can be found online at:

http://www.neurology.org/about/about_the_journal\#permissions

Information about ordering reprints can be found online:

http://n.neurology.org/subscribers/advertise

Neurology ${ }^{\circledR}$ is the official journal of the American Academy of Neurology. Published continuously since 1951 , it is now a weekly with 48 issues per year. Copyright @ 2016 American Academy of Neurology. All rights reserved. Print ISSN: 0028-3878. Online ISSN: 1526-632X.

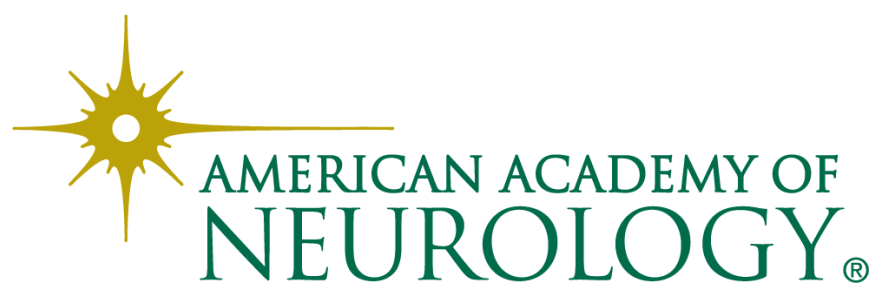

